\title{
Chlorophylls $a$ and $b$ and divinyl chlorophylls $a$ and $b$ in the open subtropical North Atlantic Ocean
}

\author{
Ralf Goericke *, Daniel J. Repeta \\ Department of Marine Chemistry and Geochemistry, Woods Hole Oceanographic Institution, Woods Hole, Massachusetts 02543, USA
}

\begin{abstract}
Divinyl chlorophyll $a$ (chl $\mathrm{a}_{2}$ ) and divinyl chlorophyll $b\left(\mathrm{chl} b_{2}\right)$ are chemotaxonomic tracers for the marine photooxytrophic procaryote Prochlorococcus marinus. Here we report the complete separation of chlorophyll a (chl $a_{1}$ ) and chl $a_{2}$ on a reverse-phase high-pressure liquid chromatography system that also achieves good separation of most other chemotaxonomically important pigments. Chlorophyll $b\left(\mathrm{chl} b_{1}\right.$ ) and chl $b_{2}$ are partially resolved, and their relative abundances are estimated with an on-line spectrophotometric method. Using these methods, we determined that chl $a_{2}$ and chl $b_{2}$ contributed up to $40 \%$ to total chl a (the sum of chl $a_{1}$ and $a_{2}$ ) and up to $95 \%$ to total chl $b$, respectively, in samples from the subtropical North Atlantic. The results suggest that Prochlorococcus represented a significant fraction of the total phytoplanktonic biomass. A comparison of chl b/a ratios observed in the field and chl $b / a$ ratios measured in cultures of $P$. marinus suggests the presence of 2 strains of this organism in the subtropical North Atlantic. The spectroscopic differences between chl $a_{1}$ and chl $a_{2}$ would have led to small underestimates of total chl $a$ in these samples had these been analyzed by spectrophotometric methods. However, the standard fluorometric method would have underestimated total chl $a$ on the average by $8 \%$ with maximum values of $20 \%$.
\end{abstract}

The newly discovered and described photooxytrophic procaryote Prochlorococcus marinus (Chisholm et al. 1988, 1992) has been detected by flow cytometry in most subtropical and tropical oceans (Chisholm et al. 1988, Li \& Wood 1988, Olson et al. 1990, Vaulot et al. 1990). Its numerical abundance is usually very high relative to other phytoplankton. However, the contribution of this very small organism $(0.6$ to $0.8 \mu \mathrm{m})$ to phytoplankton biomass has been difficult to estimate due to its unknown cellular carbon concentration. The pigment complement of $P$. marinus is unusual, because it has divinyl chlorophyll a (chl $\left.a_{2}\right)$

\footnotetext{
- Present address: Marine Life Research Group, Scripps Inst.
} of Oceanography, La Jolla, California 92093-0218, USA instead of chlorophyll a (chl $\left.a_{1}\right)$ as its major photosynthetic pigment. In addition, it has divinyl chlorophyll $b$ (chl $b_{2}$ ), possibly $2,4-\mathrm{Mg}$ divinylpheoporphyrin $a_{5}$ (Goericke \& Repeta 1992) and, in at least one strain, chlorophyll $b$ (chl $b_{1}$ ) when growth is light saturated (>40 $\mu$ Einst $\mathrm{m}^{-2} \mathrm{~s}^{-1}$; Goericke \& Moore unpubl. data). Because no other wild-type photooxytroph is known which has this pigment (Goericke \& Repeta 1992), chl $a_{2}$ is a chemotaxonomic marker for Prochlorococcus which can be used to study its distribution in the field.

Chl $a_{2}$ and chl $b_{2}$ are characterized spectrally by an 8 to $10 \mathrm{~nm}$ bathochromic shift in the Soret band when compared to $\mathrm{chl} a_{1}$ and $\mathrm{chl} b_{1}$, respectively (Goericke \& Repeta 1992). These spectral characteristics may lead to biased estimates of total chl a (i.e. the sum of chl $a_{1}$ and $a_{2}$ ) in natural samples when spectrophotometric (Jeffrey \& Humphrey 1975) or fluorometric (HolmHansen et al. 1965) methods are used to measure total chl $a$. The complete separation of chl $a_{1}$ and $a_{2}$ has only been achieved by normal-phase high-pressure liquid chromatography (Gieskes \& Kraay 1983). However, normal-phase systems are not well suited for the routine analysis of methanol or acetone extracts of natural samples. Complete separation by C-18 column-based reverse-phase high-pressure liquid chromatography (RP-HPLC), which is commonly used for the analysis of phytoplankton pigments in seawater, has not been reported (Veldhuis \& Kraay 1990).

We used a C-8 column-based RP-HPLC system, as suggested by Paerl \& Millie (1991), to achieve a complete separation of chl $a_{1}$ and chl $a_{2}$. Chl $b_{1}$ and $b_{2}$ are partially separated on this system; therefore we quantified these pigments with an on-line spectrophotometric method. These methods were used to determine the contribution of Prochlorococcus to total chl a and 
total chl $b$ in samples from the subtropical. North Atlantic.

Seawater samples (4.4 l) were collected 200 miles south of Bermuda $\left(27^{\circ} 1^{\prime} \mathrm{N}, 68^{\circ} 0^{\prime} \mathrm{W}\right)$ in January 1992 using a Niskin bottle rosette sampler. Seawater was filtered through $25 \mathrm{~mm}$ Whatman GF/F filters using a vacuum of less than $12 \mathrm{~mm} \mathrm{Hg}$. Filters were stored in liquid nitrogen and extracted in $1.5 \mathrm{ml} 100 \%$ acetone for $30 \mathrm{~min}$, ground at high speed with a Teflon pestle and extracted in the grinding tubes for an additional 30 min. Glass fibers and cell debris were separated from the acetone extract by centrifugation. We used a Waters HPLC system (Waters 660 solvent delivery system and Waters 990 diode array detector), a Rainin Dynamax $10 \mathrm{~cm} 3 \mu \mathrm{m} \mathrm{C}-8$ column and a linear binary solvent gradient for the analysis of the chlorophylls. Solvents A (MeOH:0.5 N aq. ammonium acetate, $75: 25)$ and $B(\mathrm{MeOH})$ were programmed on the following gradient (minutes; \% solvent $A, \%$ solvent $B$ ): $(0 ; 100,0),(20 ; 35,65),(30 ; 25,75),(35 ; 0,100),(40 ; 0$, $100),(45 ; 100,0)$. The coefficient of variation for replicate analyses (200 to $450 \mu \mathrm{l}$ injections) of the same pigment extract is dependent on the concentrations of the individual pigments in the extract; for the major pigments studied here it was typically in the range 2 to $5 \%$. The chromatographic system was calibrated using chlorophylls isolated from the corn mutant ON 8147. the Prochlorococcus marinus clone MED4, which does not have any detectable chl $b_{1}$, and higher plants using the extinction coefficients given in Table 1. Pigments were quantified by integrated absorbance at 440,468 or $478 \mathrm{~nm}$. Chl $b_{1}$ and $c h l b_{2}$ were estimated by peak area when the concentrations of the 2 pigments were similar enough that 2 peaks were clearly evident in the chromatogram. This was the case whenever the lesser of the 2 chlorophylis constituted more than $30 \%$ of the total. When only a single peak was evident we used an on-line spectrophotometric method in which the area of the total chl $b$ peak was measured at 468 and $478 \mathrm{~nm}, \mathrm{~A}_{468}$ and $\mathrm{A}_{478}$, respectively, and the concentrations of the 2 chlorophylls were calculated using bichromatic equations:

$\left[\mathrm{chl} b_{1}\right]=\mathrm{k}_{1} \mathrm{~A}_{468}-\mathrm{k}_{2} \mathrm{~A}_{478}, \quad\left[\mathrm{chl} b_{2}\right]=\mathrm{k}_{3} \mathrm{~A}_{478}-\mathrm{k}_{4} \mathrm{~A}_{468}$

The coefficients $k_{i}$ [ $\mu g$-pigment] were derived from detector calibrations and 468/478 $\mathrm{nm}$ on-line absorbance ratios for pure chl $b_{1}$ and $b_{2}$, using methods strictly analogous to those that are used to derive bi- or trichromatic equations used in the spectrophotometric analysis of mixtures of chlorophylls $a, b$ and $c$ (cf. Jeffrey \& Humphrey 1975); however, instead of extinction coefficients we used detector calibration constants. On the HPLC system described here, chl $b_{1}$ and chl $b_{2}$ have $468 / 478 \mathrm{~nm}$ absorbance ratios of 1.229 (standard deviation, $\mathrm{SD}= \pm 0.004, \mathrm{n}=7$ ) and $0.837(\mathrm{SD}= \pm 0.005$, $\mathrm{n}=7$ ), respectively; but it is expected that these are instrument dependent

The C- 8 column-based RP-HPLC system described here achieves a baseline separation of chl $a_{1}$ and chl $a_{2}$ (Fig. 1). Chl $b_{1}$ and chl $b_{2}$ are partially separated (Fig. 1 insert). Although it is possible to quantify the 2 pigments by peak area when both are present at similar concentrations, the on-line spectroscopic method will yield more objective results when either

Table 1. Spectral and chromatographic characteristics of the major pigments present in samples from the Sargasso Sea. $\alpha=$ weight-

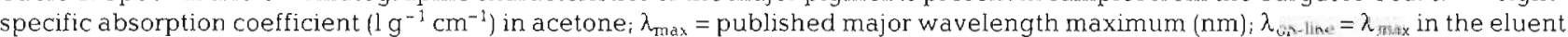
measured on-line $(\mathrm{nm}) ; t_{r}$ : retention time (min) on our C-8 RP-HPLC system (cf. Fig. 1)

\begin{tabular}{|c|c|c|c|c|c|c|}
\hline$\#$ & Pigment & $\alpha$ & $\lambda_{\max }$ & Source & $\lambda_{\text {on-line }}$ & $t_{\mathrm{r}}$ \\
\hline 1. & Chlorophyll. $c_{3}$ & nd & - & - & 458,590 & 2.7 \\
\hline 2. & Chlorophyll $c_{1.2}$ & 38.2 & 629 & (1) & $446,584,634$ & 4.7 \\
\hline 3. & Peridinin & 134 & 466 & (2) & 475 & 10.3 \\
\hline 4. & 19'-Butanoyl-oxyfucoxanthin & 145 & 449 & (3) & 446,468 & 13.4 \\
\hline 5. & Fucoxanthin & 160 & 449 & (2) & $452,(468)$ & 14.3 \\
\hline 6. & 19'-Hexanoyl-oxyfucoxanthin & 151 & 449 & (4) & 446,470 & 16.2 \\
\hline 7. & Diadinoxanthin & 225 & 448 & (5) & 442,480 & 18.1 \\
\hline 8. & Alloxanthin & 227 & 454 & (4) & 450,480 & 20.1 \\
\hline 9. & Zeaxanthin (lutein) & 234 & 452 & (2) & 450,476 & 21.6 \\
\hline 10. & Chlorophyll $b_{2}$ & 51.5 & 647 & (3) & $478,606,658$ & 28.2 \\
\hline 11. & Chlorophyll $b_{1}$ & 51.4 & 647 & (6) & $468,602,654$ & 28.4 \\
\hline 12. & Chlorophyll $a_{2}$ & 87.9 & 664 & (3) & $442,622,668$ & 33.2 \\
\hline 13. & Chlorophyll $a_{1}$ & 87.7 & 664 & (6) & $430,620,666$ & 33.8 \\
\hline 14. & $\alpha / \beta$-Carotene & - & - & - & 444,472 & 38.3 \\
\hline
\end{tabular}




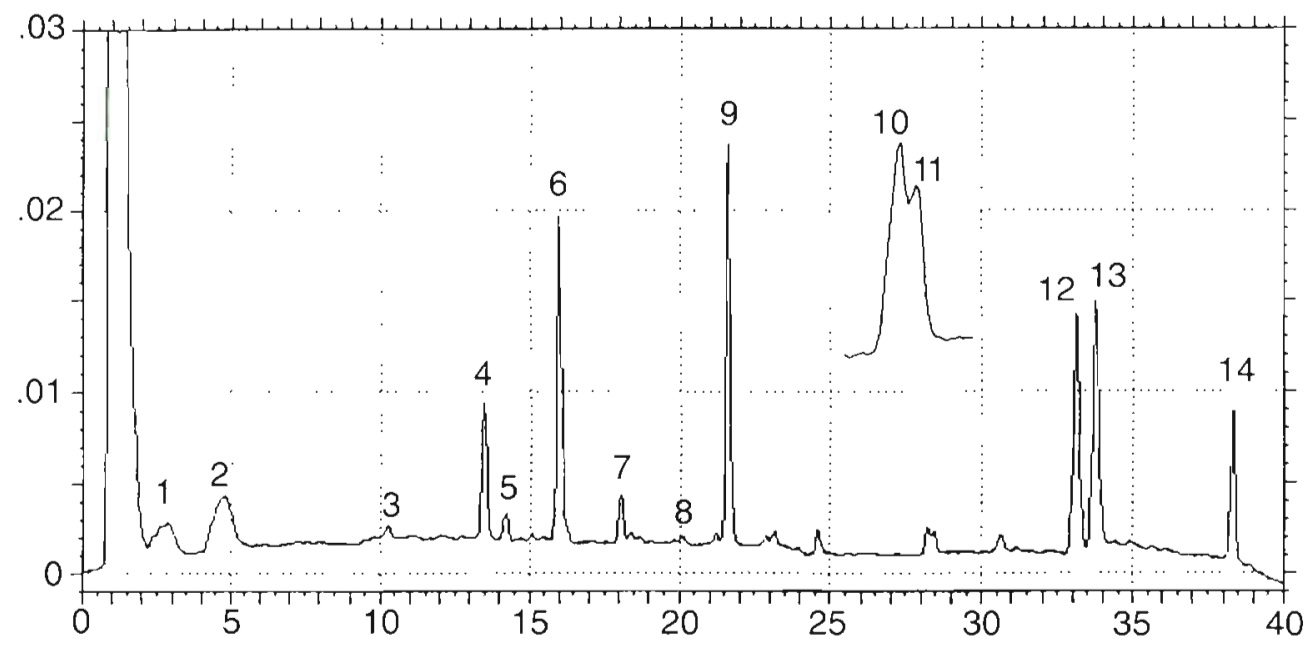

Fig. 1. Chromatogram (absorbance at $440 \mathrm{~nm}$ ) of a sample from $98 \mathrm{~m}$ in the Sargasso Sea. Note that chl $a_{1}$ and chl $a_{2}$ (peaks 12 and 13) are completely separated. The insert (absorbance at $473 \mathrm{~nm}$ ) shows the partial separation of chl $b_{1}$ and chl $b_{2}$ which elute at 28.3 min. Pigments were identified based on on-line absorbance spectra, and peak numbers correspond to numbers in Table 1. Note that it is possible to improve the separation of polar chlorophylls (chl $c_{3}$ and chl $c_{1,2}$ ) by increasing the water content of solvent $A$

of the 2 pigments dominates total chl $b$. We tested this method by analyzing mixtures of authentic chl $b_{1}$ and chl $b_{2}$ and comparing actual ratios of the 2 pigments with measured ratios (Fig. 2). The slope of a line fit to the data is $0.993(\mathrm{SD}= \pm 0.013)$ and the intercept of the line is 0.006 ( $\mathrm{SD}= \pm 0.008$ ). These results demonstrate that values of the ratio were measured in this case with a precision of $\mathrm{SD}= \pm 0.016$. However, this precision is dependent on the amount of total chl $b$ present; we estimate that the precision ranges from $\mathrm{SD}= \pm 0.02$ to \pm 0.10 in the case of our field samples (see below). Separations of most other major chlorophylls and xanthophylls by our method are similar compared to commonly used C-18 column-based systems (Mantoura \& Llewellyn 1983, Wright et al. 1991). However, the present C-8 system using our standard solvent gradient, or the solvent system of Wright et al. (1991), failed to resolve zeaxanthin and lutein and $\alpha$ - and $\beta$-carotene.

We used this chromatographic system to analyze pigment samples from the southern Sargasso Sea. The water column was stratified at the time of sampling, and the in vivo fluorescence profile showed a pronounced maximum below $100 \mathrm{~m}$ (Fig. 3). Chl $a_{1}$ and chl $a_{2}$ were present from the surface to $200 \mathrm{~m}$ (Fig. 4A), but were undetectable at $250 \mathrm{~m}$. Their concentration maximum, i.e. the subsurface chlorophyll maximum (SCM), was located at $116 \mathrm{~m}$ (Fig. 4A). The ratio of chl $a_{2}$ to total chl $a$ ranged from about 0.25 in the surface layer to 0.4 at the SCM (Fig. 4B). Chl $b_{1}$ had a distribution similar to chl $a_{1}$ (Fig. 4 C). The ratio of chl $b_{1}$ to chl $a_{1}$ was about 0.08 and did not vary systematically as a function of depth (data not shown). The concen- tration of chl $b_{2}$ varied by almost 2 orders of magnitude as a function of depth (Fig. $4 \mathrm{C}$ ). The ratio of $\mathrm{chl} b_{2}$ to total chl $b$ ranged from 0.35 in the surface layer to 0.95 at and below the SCM (Fig, 4B).

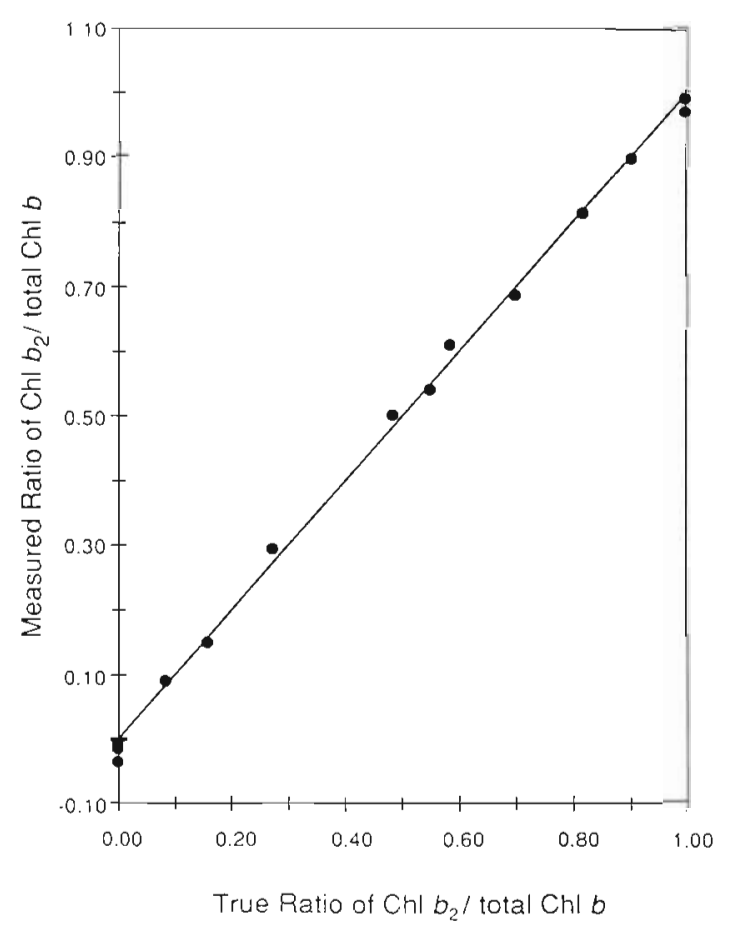

Fig. 2. True and measured values of the ratio of $\mathrm{chl} b_{2}$ to total chl $b$. The measured ratio was determined from integrated total chl $b$ absorbances at 468 and $478 \mathrm{~nm}$, as described in the text 


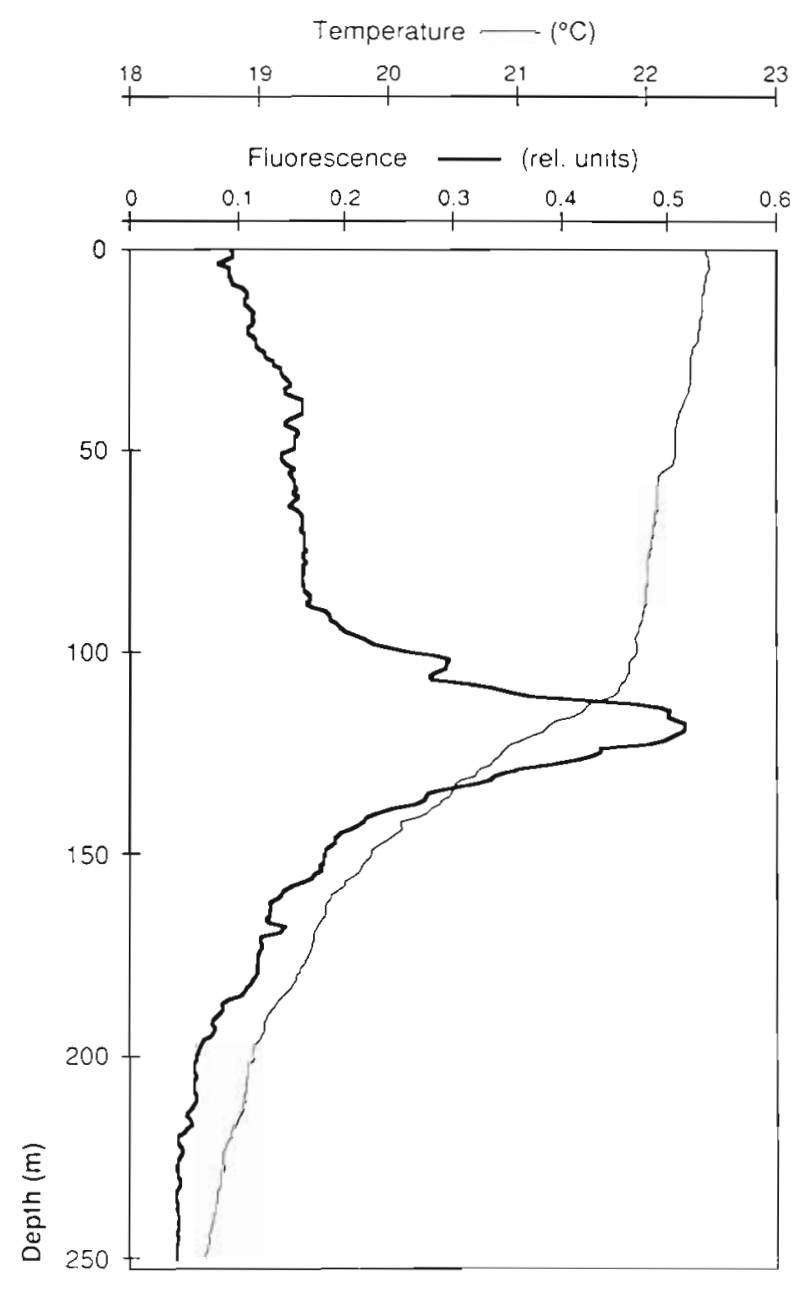

Fig. 3. Depth profiles of temperature and induced in situ fluorescence at a station (EN232C02) $300 \mathrm{~km}$ south of Bermuda

These results clearly illustrate the importance of Prochlorococcus in the subtropical open ocean. Assuming that carbon to chl ratios were similar for Prochlorococcus and other phytoplankton (i.e. cyanobacteria and eucaryotic microalgae), these data suggest that the contribution of Prochlorococcus to phytoplankton biomass ranged from ca $25 \%$ of the total in the surface layer to ca $40 \%$ of the total at the SCM. These data corroborate the results of Goericke \& Welschmeyer (1993b) who reported that Prochlorococcus was present at a station southeast of Bermuda throughout the year with the exception of one observation in February 1987. They calculated values of relative Prochlorococcus pigment-biomass (i.e. chl $a_{2}$ as a \% of total chl a) ranging from less than $10 \%$ to $75 \%$ of the total. These results also lend support to the conclusions of Olson et al. (1990), Vaulot et al. (1990), and Veldhuis \& Kraay (1990) that Prochlorococcus is ubiquitously present in the tropical and subtropical ocean, often representing a significant fraction of phytoplankton biomass. Our results suggest that Prochlorococcus pigment-biomass can be similarly important in the surface layer and at the SCM, consistent with reports by Olson et al. (1990) of relatively high concentrations of Prochlorococcus in the upper euphotic zone of the Sargasso Sea in late fall and winter.

Our data (Fig 4B) demonstrate as well that Prochlorococcus can be the major contributor to total chl $b$ in the subtropical open ocean, particularly at the SCM. These results question the conclusions of others who have ascribed the total chl $b$ signal in subtropical areas entirely to green algae (e.g. Jeffrey 1976). Attribution of chl $b_{1}$ to specific groups of phytoplankters is difficult because chl $b_{1}$ is not only found in chlorophytes, prasinophytes and euglenophytes but also in high light grown cultures of the $P$. marinus clone SS120 (Goericke \& Moore unpubl.). Thus, our data suggest that eucaryotes containing $c h l b_{1}$, which are characterized by chl $b_{1} / a_{1}$ ratios ranging from 0.05 to 0.5 (Wood 1979), represented a small but significant fraction of the total pigment-biomass at and below the SCM $C h l b_{1}$ present above the SCM may have been associated with eucaryotes and Prochlorococcus.

The ratio of chl $b_{2}$ to $\mathrm{chl} a_{2}$ ranged from ca 0.15 in the surface layer to 2.9 below the SCM, and the ratio of total chl $b$ to chl $a_{2}$ ranged from 0.3 in the surface layer to 3.0 below the SCM (Fig. 5); a range of chl $b / a$ values not observed in any culture study with eucaryotes (Wood 1979) or Prochlorococcus marinus (Partensky et al. 1993, Moore et al. unpubl.). The large variation of the $b_{2} / a_{2}$ ratio in our field samples indicates either that the observed population of Prochlorococcus has an unusual capacity for physiological adaptation or that different species or strains of Prochlorococcus, with differing $b_{2} / a_{2}$ ratios, were present. Culture studies point to the latter possibility, since $b / a$ ratios differed in cultures of $P$. marinus clones SS120 (isolated from the SCM of the Sargasso Sea) and MED4 (isolated from the surface layer of the Mediterranean) by a factor of 8 (Moore et al. unpubl.). Values of the $\mathrm{chl} b / a$ ratio for the $P$. marinus clone SS120 (solid bold line in Fig. 5) were similar to values measured in the field at and below the SCM, whereas values of the chl b/a ratio for the clone MED4 (broken bold line in Fig. 5) were slightly less than values of the $b_{2} / a_{2}$ ratio measured in the surface layer. These results suggest that 2 different strains or species of Prochlorococcus were present in the Sargasso Sea; a suggestion which can be corroborated using molecular probes.

The application of spectrophotometric or fluorometric methods for the measurement of total chl a may have resulted in biased estimates of total chl a for these samples due to the spectral differences between $c h l a_{1}$ and chl $a_{2}$. The weight-specific absorption coefficient of chl $a_{2}$ in $80 \%$ acetone at $664 \mathrm{~nm}$ was measured by 


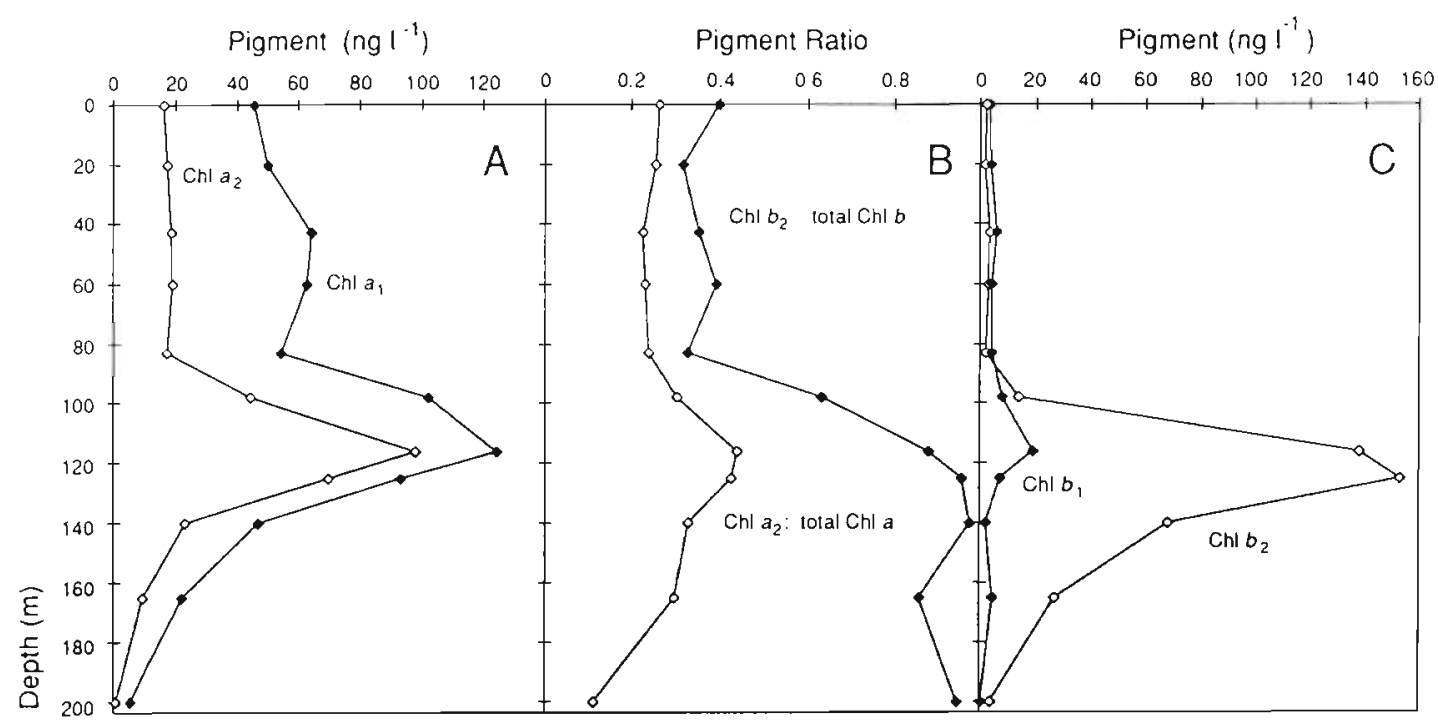

Fig. 4. Depth profiles of (A) concentrations of chl $a_{1}(\diamond)$ and chl $a_{2}(\diamond)$, (B) the ratios chl $b_{2}$ : total chl $b(\diamond)$ and chl $a_{2}:$ total chl $a$ $(\diamond)$, and $(C)$ concentrations of $\mathrm{chl} b_{1}(\diamond)$ and $\operatorname{chl} b_{2}(\diamond)$

Shedbalkar \& Rebeiz (1992) as $77.71 \mathrm{~g} \mathrm{~g}^{-1} \mathrm{~cm}^{-1}$, a value which is probably not significantly different from the extinction coefficient of chl $a_{1}$ in $80 \%$ acetone $(89.2$ l

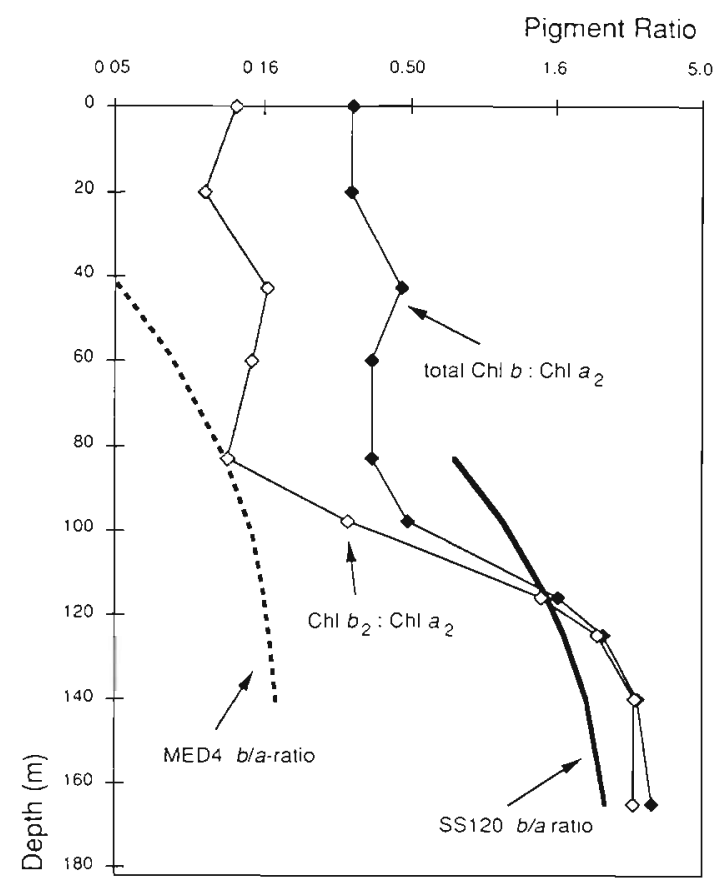

Fig. 5. Depth profiles of the ratios chl $b_{2}: \operatorname{chl} a_{2}(\diamond)$ and total chl $b: \operatorname{chl} a_{2}($ ). Note that the $\mathrm{x}$-axis is scaled logarithmically. Variations of total chl $b$ :chl $a_{2}$ ratios with irradiance for Prochlorococcus marinus clones SS120 (solid line) and MED4 (broken line) as determined by Moore et al. (unpubl.) are included. The length of these lines corresponds to the range of light intensities at which these strains were grown successfully $\mathrm{g}^{-1} \mathrm{~cm}^{-1}$; Jeffrey et al. 1974) because the chl $a_{2}$ preparation used for the determination of the extinction coefficient by Shedbalkar \& Rebeiz was slightly (ca $5 \%$ of the pigment) contaminated with lipids. However, our data show that the extinction coefficients at the Soret maxima differ, since the ratios of the absorbances at the Soret and red maxima (S/R ratios) are significantly different $(p<0.0001$ ) for the 2 chlorophylls ( $S / R$ ratio for chl $a_{1}: 1.24 \pm 0.02(95 \% \mathrm{CI})$ and chl $\left.a_{2}: 1.41 \pm 0.004\right)$. These results imply that standard spectrophotometric methods for the measurement of total chl a (e.g. Jeffrey $\&$ Humphrey 1975) are biased negligibly (<9\%) when equal amounts of chl $a_{1}$ and chl $a_{2}$ are present because these methods rely on absorbance measurements in the red. However, measurements of total chl a by

Table 2. Fluorescence response factors $\left(K_{\mathrm{f}}\right)$ and acid ratios $(\tau)$ for pigments analyzed on a Turner Designs Model 10 fluorometer equipped for chlorophyll analysis (Holm-Hansen et al. 1965). $K_{\mathrm{fl}}$ is the fluorescence of a solution of the pigment normalized by its concentration $\left(\mu \mathrm{g} \mathrm{ml}^{-1}\right)$. The acid ratio is the ratio of the fluorescence before and after acidification of the sample with 2 drops of $0.1 \mathrm{~N} \mathrm{HCl}$. The chlorophyll a ( $\mathrm{chl}_{\text {fluor }}$ ) and pheopigment ( $\mathrm{pheo}_{\mathrm{fluor}}$ ) equivalents of each pigment are calculated assuming the fluorometer was calibrated with pure chl $a_{1}$. Equivalents are given as $\mathrm{g} \mathrm{chl} a_{1}$ and $\mathrm{g}$ 'pheopigment' simulated by $1 \mathrm{~g}$ of the pigment

\begin{tabular}{|rrccc|}
\hline Pigment & \multicolumn{1}{c}{$K_{\mathrm{fl}}$} & $\tau$ & chl $_{\text {fluor }}$ & pheo $_{\text {fluse }}$ \\
\hline Chl $a_{1}$ & 19.8 & 2.10 & 1.00 & 0.00 \\
Chl $a_{2}$ & 22.9 & 1.89 & 1.04 & 0.24 \\
Chl $b_{1}$ & 5.0 & 0.63 & -0.28 & 1.13 \\
Chl $b_{2}$ & 4.7 & 0.58 & -0.33 & 1.20 \\
\hline
\end{tabular}


HPLC can be severely biased when chl $a_{1}$ and $a_{2}$ are not separated and quantified by absorbance at $440 \mathrm{~nm}$ (Bidigare 1991). On our C-18 RP-HPLC system (Goericke \& Repeta 1992) total chl a is overestimated by $20 \%$ when equal amounts of chl $a_{1}$ and $a_{2}$ are present.

We also determined the response of a fluorometer to chlorophylls $a_{1}, a_{2}, b_{1}$, and $b_{2}$ in order to estimate the bias due to the spectral differences between the chlorophylls when total chl a is measured fluorometrically (Holm-Hansen et al. 1965). The fluorescence response factor of chl $a_{2}$ was slightly higher than the factor for chl $a_{1}$ (Table 2), and the acid ratio of chl $a_{2}$ i.e. the fluorescence before and after acidification with dilute $\mathrm{HCl}$ (cf. Holm-Hansen et al. 1965), was 10\% lower. Thus, $1 \mathrm{~g}$ chl $a_{2}$ will simulate $1.04 \mathrm{~g} \mathrm{chl} a_{1}$ and $0.24 \mathrm{~g}$ 'pheopigment' on our fluorometer which was calibrated with chl $a_{1}$ (Table 2). The response factors and acid ratios of chl $b_{1}$ and chl $b_{2}$ were very similar; the presence of $1 \mathrm{~g}$ of either pigment simulated about $-0.3 \mathrm{~g} \mathrm{chl} a_{1}$ and slightly more than $1 \mathrm{~g}$ 'pheopigment' (Table 2). In the case of our samples from the Sargasso Sea, the spectral differences between chl $a_{1}$ and chl $a_{2}$ and the presence of chl $b_{1}$ and chl $b_{2}$ would have led on the average to an $8 \%$ underestimation of total $\mathrm{chl} a_{\text {, }}$ with maximal values of $20 \%$. These results show that the spectral differences between chl $a_{1}$ and chl $a_{2}$ can bias the fluorometric methods for the measurement of total chl a. However, this bias is small when compared to commonly observed differences between fluorometrically determined total chl a and total chl a determined by HPLC (Trees et al. 1985, Goericke 1990).

A consequence of the very high concentrations of chl $b_{1}$ and chl $b_{2}$ in our samples would have been a severe overestimation of 'pheopigment' concentrations by the fluorometric method (Loftus \& Carpenter 1971, Vernet \& Lorenzen 1987). Whereas we did not observe any significant quantities of pheophorbides or pheophytins (absorbance detection at $668 \mathrm{~nm}$ ) in these samples, the fluorometric method would have given total chl a: pheopigment ratios larger than 1.0 below the SCM. These results corroborate the conclusion of Herbland (1988) that the deep pheopigment maxima usually observed in subtropical and tropical oceans are an 'illusion' rather than 'reality' due to the very high concentrations of total chl $b$ at the bottom of the euphotic zone. However, it is likely that estimates of 'pheopigments' in the surface layer of the open subtropical and tropical ocean are significantly affected by the presence of total chl $b$ as well, because concentrations of 'pheopigments' are often very small or at least of similar magnitude as concentrations of total chl $b$ (Gieskes 1991, Goericke unpubl obs.).

To conclude, the C-8 column-based RP-HPLC system described here achieves a complete separation of chl $a_{1}$ and chl $a_{2}$ and a partial separation of chl $b_{1}$ and chl $b_{2}$. The separation of most other chemotaxonomically important pigments is as good as separations achieved on C-18 column based systems. Measurements of total chl a and, in particular, 'pheopigment' can be significantly biased when traditional methods are used to determine total chl $a$ in samples from the open subtropical and tropical ocean where Prochlorococcus is abundant. It is necessary to separate chl $a_{1}$ and chl $a_{2}$ chromatographically when concentrations of total chl a are to be measured accurately. The application of this method to the analysis of pigment samples from the subtropical and tropical open ocean will lead to a better understanding of the role of Prochlorococcus in the marine environment; results of this study, for example, suggest that 2 different strains of Prochlorococcus are present in the Sargasso Sea.

Acknowledgements. We thank Eric Zettler, Rob Olson and the crew of the RV 'Endeavor' for help during sample collection, Michele Durand for processing CTD data, and C. Arnosti for critical reading of the manuscript. This research was supported by NSF grant OCE 91-01384 to D.J.R. and R.G and NASA grant NAGW-2431 to D.J.R. This is Woods Hole Oceanographic Institution contribution number 8501

\section{LITERATURE CITED}

Bidigare, R. R. (1991). Analysis of algal chlorophylls and carotenoids. In: Hurd, D. C., Spencer, D. W. (eds.) Marine particles: analysis and characterization. American Geophysical Union, Washington, DC, p. 119-123

Chisholm, S. W., Frankel, S., Goericke, R., Olson, R., Palenik, B., Urbach, E., Waterbury, J., Zettler, E. (1992). Prochlorococcus marinus nov. gen. nov. sp.: an oxyphototrophic marine prokaryote containing divinyl chlorophyll $a$ and $b$. Arch. Microbiol. 157: 297-300

Chisholm, S. W., Olson, R. J., Zettler, E. R., Goericke, R. Waterbury, J. B., Welschmeyer, N. A. (1988). A novel freeliving prochlorophyte abundant in the oceanic euphotic zone. Nature 334: 340-343

Gieskes, W. W C. (1991). Algal pigment fingerprints: clue to taxon-specific abundance, productivity and degradation of phytoplankton in seas and oceans. In: Demers, S. (ed.) Particle analysis in oceanography. Springer, Berlin, p. $60-99$

Gieskes, W. W. C., Kraay, G. W. (1983). Unknown chlorophyll a denvatives in the North Sea and the tropical Atlantic Ocean revealed by HPLC analysis. Limnol. Oceanogr. 28: $757-766$

Goericke, R. (1990). Pigments as ecological tracers for the study of the abundance and growth of marine phytoplankton. Ph.D. thesis, Harvard University, Cambridge, p. 418

Goericke, R., Repeta, D. J. (1992). The pigments of Prochlorococcus marinus: the presence of divinyl chlorophyll $a$ and $b$ in a marine prochlorophyte. Limnol. Oceanogr. 37. $425-433$

Goericke, R., Welschmeyer, N. A. (1993a). The carotenoidlabeling method: measuring specific rates of carotenoid synthesis in natural phytoplankton communities. Mar. Ecol. Prog. Ser. 98: 157-171

Goericke, R., Welschmeyer, N. A. (1993b). Prochlorophyte picoplankton contribute significantly to biomass and pri- 
mary production in the Sargasso Sea. Deep Sea Res. (in press)

Herbland, A. (1988). The deep phaeopigment maximum in the ocean: reality or illusion? In: Rothschild, B. J. (ed.) Toward a theory on biological-physical interactions in the world ocean. Kluwer Academic, Amsterdam, p. 157-172

Holm-Hansen, O., Lorenzen, C. J., Holmes, R. W., Strickland, J. D. H. (1965). Fluorometric determination of chlorophyll. J. Cons. perm. int. Explor. Mer 30: 3-15

Jeffrey, S. W. (1972). Preparation and some properties of crystalline chlorophyll $c_{1}$ and $c_{2}$ from marine algae. Biochim. Biophys. Acta 279: 15-33

Jeffrey, S. W. (1976). A report of green algal pigments in the central North Pacific Ocean. Mar. Biol. 37: 33-37

Jeffrey, S. W., Douce, R., Benson, A. A. (1974). Carotenoid transformations in the chloroplast envelope. Proc. natl Acad. Sci. U.S.A. 71: 807-810

Jeffrey, S. W., Humphrey, G. F. (1975). New spectrophotometric equations for determining chlorophylls $a, b, c_{1}$, and $c_{2}$ in higher plants, algae and natural phytoplankton. Biochem. Physiol. Pflanz. 167 191-194

Jensen, A. (1978). Chlorophylls and carotenoids. In: Helleburst, J. A., Craigie, J. S. (eds.) Handbook of phycological methods: physiological and biochemical methods. Cambridge Univ. Press, Cambridge, p. 59-70

Johansen, J. E., Svec, W. A., Liaaen-Jensen, S. (1974). Carotenoids of the dinophyceae. Phytochem. 13: 2261-2271

Li, W. K. W., Wood, A. M. (1988). Vertical distribution of North Atlantic ultraphytoplankton: analysis by flow cytometry and epifluorescence microscopy. Deep Sea Res. 35: $1615-1638$

Loftus, M. E., Carpenter, J. H. (1971). A fluorometric method for determining chlorophylls $a, b$ and $c$. J. mar. Res. 29: 319-338

Mantoura, R. F. C., Llewellyn, C. A. (1983). The rapid determination of algal chlorophyll and carotenoid pigments and their breakdown products in natural waters by reverse phase high performance liquid chromatography. Analytica chim. Acta 151: 297-314

This note was presented by D. A. Caron, Woods Hole, Massachusetts, USA
Olson, R. J., Chisholm, S. W., Zettler, E. R., Altabet, M. A., Dusenberry, J A. (1990). Spatial and temporal distributions of prochlorophyte picoplankton in the North Atlantic Ocean. Deep Sea Res. 37 1033-1051

Paerl, H. W., Millie, D. F. (1991). Evaluations of spectrophotometric, fluorometric and high performance liquid chromatographic methods for algal pigment determinations in aquatic ecosystems. Workshop Report to EPA, Edison, NJ

Partensky, F., Hoepfner, N., Li, W. K. W., Ulloa, O., Vaulot, D. (1993). Photoacclimation of Prochlorococcus sp. (Prochlorophyta) strains isolated from the North Atlantic and the Mediterranean Sea. Plant Physiol. 101:285-296

Shedbalkar, V. P., Rebeiz, C. A. (1992). Chloroplast biogenesis: determination of the molar extinction coefficients of divinyl chlorophyll $a$ and $b$ and their pheophytins. Analyt Biochem. 207: in press

Trees, C. C., Kennicutt, M. C., Brooks, J. M. (1985). Errors associated with the standard fluorometric determination of chlorophylls and pheopigments. Mar Chem. 17: $1-12$

Vaulot, D., Partensky, F., Neveux, J., Mantoura, R. F. C., Llewellyn, C. A. (1990). Winter presence of prochlorophytes in surface waters of the northwestern Mediterranean Sea. Limnol. Oceanogr. 35: 1156-1154

Veldhuis, M. J. W., Kraay, G. W. (1990). Vertical distribution and pigment composition of a picoplanktonic prochlorophyte in the subtropical North Atlantic: a combined study of pigments and flow cytometry. Mar. Ecol. Prog. Ser. 68: 121-127

Vernet, M., Lorenzen, C. J (1987). The presence of chlorophyll $b$ and the estimation of pheopigments in marine phytoplankton. J. Plankton Res. 9: 255-265

Wood, A. M. (1979). Chlorophyll a: b ratios in marine planktonic algae. J. Phycol. 15: 330-332

Wright, S. W., Jeffrey, S. W., Mantoura, R. F. C., Llewellyn, C. A., Bjornland, T., Repeta, D., Welschmeyer, N. (1991). Improved HPLC method for the analysis of chlorophylls and carotenoids from marine phytoplankton. Mar Ecol. Prog. Ser. 77: 183-196

Manuscript first received: December 20, 1992

Revised version accepted: July 22, 1993 